\title{
SIMPLIFICATION OF THE EUROPEAN MODEL OF MANAGEMENT EXCELLENCE
}

\author{
Aurelio Muñoz Rubio ${ }^{1 *}$, Fernando Tejedor-Panchón² ${ }^{2}$ Gonzalo Tejedor-Panchón ${ }^{3}$, José Manuel Mánuel ${ }^{4}$, \\ Francisco Javier Bermúdez Rodríguez ${ }^{5}$, Ricardo Hernández Molina ${ }^{6}$ \\ *I Escuela de Ingeniería Naval, University of Cadiz, CASEM, Puerto Real (Spain) \\ ${ }^{2}$ Sinergy Ltd. Sevilla (Spain) \\ ${ }^{3}$ Gisa Ltd. Rota (Spain) \\ ${ }^{4}$ IMEYMAT: Institute of Research on Electron Microscopy and Materials. University of Cadiz, Puerto Real (Spain) \\ ${ }^{5,6}$ Acoustic Engineering Laboratory, CASEM. University of Cadiz, Puerto Real (Spain) \\ ${ }^{1}$ aurelio.munioz@uca.es; ${ }^{2}$ tejedor@ sinergy.es; ${ }^{3}$ gtejedor@ gisasl.es; ${ }^{4}$ jose.manuel@uca.es; ${ }^{5}$ javier.bermudez@uca.es, \\ ricardo.hernandez@uca.es \\ *Corresponding Author: - \\ Email: aurelio.munioz@uca.es

\begin{abstract}
: -
The current international context requires the modernization of the naval sector towards what has been called Naval Industry 4.0, which has already been successfully implemented by some countries such as North Korea. In order to remain competitive with those countries, a deep reconsideration of the engineering of the whole value chain must be done. Thus, the optimization of each one of the naval sector elements is highly important. These changes also include the auxiliary industry needed for a dynamic dockyard. More specifically, the working and management model of such industry has to be updated and improve its efficiency by involving business models that guarantee the management excellence. In this sense, one management model that has become a reference for many organizations is the European Model of Excellence. In this work, we present a simplification of this model, which would allow implementing it in SMEs.
\end{abstract}

Keywords: - EFQM Model, Structural Equation Modeling (SEM), Total Quality (TQ), Enabler Criteria, Performance Criteria

\section{(c) $(\$)$}




\section{INTRODUCTION}

Since the European Foundation for Quality Management (EFQM) developed the first version of the EFQM Model, the use of this model has been increasing as a reference for the annual evaluation of the candidate organizations for the European Quality Award. Complementary to the Award, the EFQM has established a recognition system for the level of management excellence achieved by organizations through a formal process of evaluation and ranking. By the end of 2014, there were a total of 3,483 organizations recorded on the EFQM website with some type of recognition on the reached level of excellence thanks to this Model [1].

A scheme showing the different links in the EFQM Model is shown in Figure 1, in which particular elements of the management of an organization, known as "Enablers Criteria", would be the causal factors of the performance or results produced for each group of stakeholders (named "Results Criteria" in the Model). Thus, according to EFQM "excellent results in the overall performance of an Organization, in respect of its Customers, People and in the Society in which it operates, are achieved by Leadership that directs and drives the Policy and Strategy, which will be realized through the People, Partnership, Resources and Processes." [2]

However, although this Model embodies generally accepted principles in the field of Total Quality Management, the formulation of the EFQM Model does not derive from any empirical study [3,4]; what is more, identifying up to 9 Criteria (as shown in Figure 1) and dividing them into many more sub-criteria has usually been done without any previous tests or empirical studies.

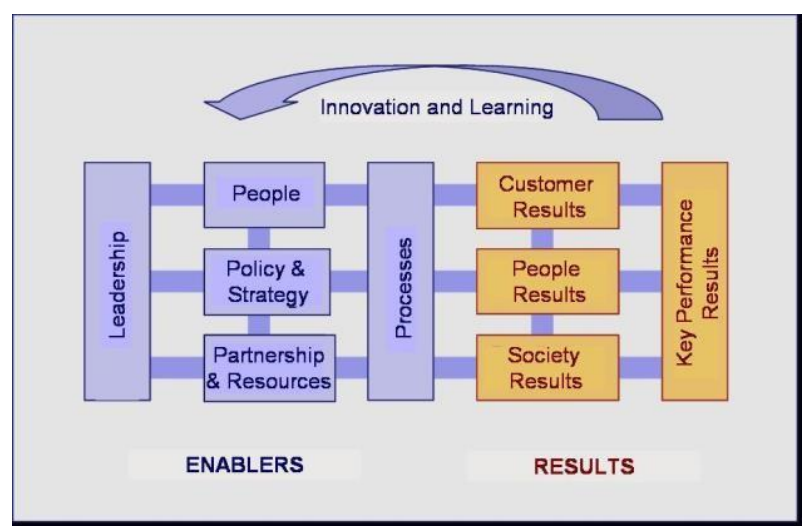

Figure 1. EFQM Model.

A certain systematic approach can be appreciated in the division of each of the 4 Performance Criteria into 2 sub-criteria, each of them associated with direct measurements, or with indicators of the performance or results for a specific group of stakeholders. However, the 5 Enabler Criteria are divided into 24 sub-criteria that correspond to the consensus regarding which practices are considered to be management practices of excellence, reached among the groups of experts who participated in their design.

The methodology of evaluation recommended by EFQM, in the processes in which greater precision is required, involves the use of matrices that include diverse aspects to be evaluated in each of the 32 sub-criteria. The result is that the EFQM evaluation process can demand considerable effort and attention by an organization in locating and analyzing information [5]. This limits its utilization as an instrument for the continuous monitoring of the evolution of management and of the performance of an organization in cyclical processes of self-evaluation, especially in an organization with serious limitations of resources, particularly a Small and Medium-size Enterprise (SME) in the naval sector [6].

The object of the present study is to identify a Simplified Model, based on the sub-criteria of the full EFQM Model, that would require less effort and time dedicated to carry out the evaluation of the level of excellence in management achieved by an organization, and that would allow the improvement to be focused on the reduced number of dimensions considered. This Simplified Model would require less effort and time to carry out the evaluation of the level of excellence in management achieved by an organization, and that would allow improvement to be focused on the reduced number of dimensions considered.

\section{Methodology}

Factorial analysis is a statistical technique that enables homogeneous groups of variables to be found from a numerous set of variables. These homogeneous groups are constructed with the variables that present a high degree of correlation with each other, while at the same time ensuring that the resulting groups are independent of each other. Consequently, factorial analysis allows the user to select the minimum number of dimensions capable of explaining the maximum amount of information contained in the data.

The present study uses the technique of factorial analysis to group together the 24 enabler sub-criteria of the EFQM Model in a reduced number of dimensions. It thus seeks to simplify this Model with respect to the initial 5 Enabler Criteria.

The goodness of the fit between the data observed and a factorial model can be evaluated by means of the Kaiser-MeyerOlkin (KMO) measure of sampling adequacy [7,8,9], which compares the magnitude of the observed correlation coefficients with the partial correlation coefficients. The closer the KMO index value is to 1, the better the data correspond to a factorial structure. By convention, when the KMO value is below 0.6, the fit is considered poor. Factorial analysis and the calculation of the KMO index have been performed using the statistical package SPSS. 
Structural Equation Modeling (SEMs) have also been used, in this study, to evaluate the fit of the EFQM Simplified Model to the data, in comparison with the original EFQM Model. SEMs constitute a general framework for the statistical analysis of the relationships between different variables. The purpose, in accordance with Ullman [10], is to allow "the examination of a set of relationships between one or more independent variables and one or more dependent variables". The variables can, in turn, be measured variables or latent variables. The measured variables, also known as observed variables or indicators, are variables that can be observed and measured directly. The latent variables are variables that cannot be observed directly, and that have to be inferred from their effects on the observed variables. Latent variables are also known as constructs (sociology), factors (factorial analysis) or non-observed variables.

This technique is well adapted to the analysis of the structure of the EFQM Model, since it includes a methodology for achieving the degree of excellence in each one of the sub-criteria of the EFQM Model. If the Criteria of the Model are considered as latent variables, the scores of each related sub-criterion can be used as indicators of the degree of excellence achieved in that particular Criterion.

To evaluate how close the models are to the data, several different indices of Goodness of Fit have been selected, as summarized in Table 1.

Table I.

Indices of goodness of fit of the Model to the experimental data.

\begin{tabular}{|l|l|}
\hline Index & Criterion of evaluation \\
\hline CMIN/DF & Values of 3 or less would indicate an acceptable fit. \\
\hline GFI & By convention, this must be higher than or equal to 0.90 for the model to be accepted. \\
\hline CFI & By convention values, equal to or higher than 0.90 indicate an acceptable fit. \\
\hline RMSEA & By convention values, less than or equal to 0.08 indicate an adequate fit. \\
\hline ECVI & The lower the value, the better the fit. \\
\hline
\end{tabular}

The parameters of the SEMs and the coefficients of Goodness of Fit has been calculated estimated using the statistical package AMOS. On the other hand, the study has been based on the scores corresponding to evaluations of 168 candidatures presented to the Andalusian Award for Excellence in the calls in the years 2002 and 2003, and to the Basque Silver and Gold Award for Quality of Management in the calls in the years 2001, 2002 and 2003. The EFQM Model 2003 version was used in the evaluations.

The methodology of evaluation utilized is based in the REDER logical scheme (Results, Focus, Deployment, Evaluation and Review). Along the evaluation process of the EFQM Awards for excellence, each candidate organization reports a series of activities and performances, describing how each of the Enabler sub-criteria is addressed, and what performance is achieved for each of the Results sub-criteria. On the basis of this report, each Sub-criterion is given a score between 0 and 100 by means of an assessment matrix. In accordance to which, for each one of the Enabler sub-criteria, the management approach utilized for achieving the planned results is assessed. This evaluation takes into account how the resources have been deployed, how the approach was assessed and reviewed in function of its effectiveness, and how the approach is improved by means of innovation and learning. In the Results sub-criteria, assessments are quantified with reference to (i) how satisfactory the outcome has been and the solidity of the trends, (ii) the compliance with the organization's own objectives, (iii) the comparison with the performance of other organizations, and (iv) the degree of causality between the management approaches adopted and the results or achieved outcomes. The extent to which the performance achieved covers all the relevant areas is also assessed.

Table 2 shows the coefficients for the evaluation of the normality of the distributions of the scores by each sub-criterion. Since the multivariate coefficient of kurtosis is found to be significantly different from zero in all cases, the hypothesis according to which the scores by sub-criterion follow a multivariate normal distribution is rejected. 
Table II.

Evaluation parameters of the scores normality for each sub-criterion.

\begin{tabular}{|c|c|c|c|c|c|c|}
\hline Variable & $\min$ & $\max$ & skew & c.r. & kurtosis & c.r. \\
\hline $1 \mathrm{a}$ & 5.000 & 85.000 & 0.140 & 0.740 & -0.259 & -0.684 \\
\hline $1 b$ & 5.000 & 85.000 & 0.100 & 0.530 & -0.178 & -0.470 \\
\hline $1 \mathrm{c}$ & 0.000 & 85.000 & 0.405 & 2.141 & 0.642 & 1.698 \\
\hline $1 d$ & 5.000 & 85.000 & 0.576 & 3.046 & 0.534 & 1.414 \\
\hline $2 a$ & 0.000 & 85.000 & 0.098 & 0.520 & -0.035 & -0.092 \\
\hline $2 b$ & 0.000 & 85.000 & 0.057 & 0.302 & -0.266 & -0.703 \\
\hline $2 \mathrm{c}$ & 5.000 & 85.000 & -0.069 & -0.364 & -0.434 & -1.148 \\
\hline $2 d$ & 0.000 & 90.000 & 0.241 & 1.275 & -0.259 & -0.685 \\
\hline $2 \mathrm{e}$ & 0.000 & 85.000 & 0.257 & 1.357 & 0.165 & 0.436 \\
\hline $3 a$ & 5.000 & 85.000 & 0.062 & 0.326 & -0.147 & -0.389 \\
\hline $3 b$ & 5.000 & 80.000 & 0.253 & 1.336 & -0.314 & -0.832 \\
\hline $3 c$ & 0.000 & 85.000 & 0.362 & 1.915 & -0.155 & -0.411 \\
\hline $3 d$ & 10.000 & 90.000 & 0.258 & 1.363 & 0.246 & 0.650 \\
\hline $3 \mathrm{e}$ & 0.000 & 85.000 & 0.189 & 1.000 & -0.082 & -0.217 \\
\hline $4 a$ & 5.000 & 85.000 & 0.052 & 0.273 & -0.174 & -0.460 \\
\hline $4 \mathrm{~b}$ & 0.000 & 85.000 & -0.127 & -0.674 & -0.066 & -0.175 \\
\hline $4 c$ & 0.000 & 85.000 & -0.053 & -0.283 & -0.193 & -0.510 \\
\hline $4 d$ & 0.000 & 90.000 & 0.309 & 1.634 & 0.168 & 0.445 \\
\hline $4 \mathrm{e}$ & 5.000 & 90.000 & 0.440 & 2.326 & 0.636 & 1.684 \\
\hline $5 \mathrm{a}$ & 5.000 & 95.000 & -0.065 & -0.344 & -0.063 & -0.166 \\
\hline $5 b$ & 5.000 & 90.000 & 0.413 & 2.186 & 0.379 & 1.004 \\
\hline $5 \mathrm{c}$ & 5.000 & 90.000 & 0.185 & 0.980 & -0.310 & -0.821 \\
\hline $5 d$ & 5.000 & 90.000 & -0.012 & -0.062 & -0.381 & -1.009 \\
\hline $5 e$ & 10.000 & 85.000 & 0.306 & 1.617 & -0.009 & -0.023 \\
\hline $6 a$ & 0.000 & 90.000 & 0.429 & 2.268 & -0.137 & -0.362 \\
\hline $6 b$ & 5.000 & 85.000 & 0.628 & 3.322 & 0.555 & 1.469 \\
\hline $7 \mathrm{a}$ & 0.000 & 65.000 & 0.409 & 2.164 & -0.505 & -1.336 \\
\hline $7 b$ & 0.000 & 70.000 & 0.489 & 2.586 & 0.219 & 0.579 \\
\hline $8 \mathrm{a}$ & 0.000 & 90.000 & 1.471 & 7.786 & 3.537 & 9.358 \\
\hline $8 b$ & 0.000 & 75.000 & 0.618 & 3.269 & 0.658 & 1.740 \\
\hline $9 \mathrm{a}$ & 0.000 & 85.000 & 0.308 & 1.632 & -0.169 & -0.447 \\
\hline $9 \mathrm{~b}$ & 0.000 & 85.000 & 0.465 & 2.463 & -0.025 & -0.066 \\
\hline Multivariate & & & & & 239.349 & 33.253 \\
\hline
\end{tabular}

Since the data for the study do not fit a multivariate normal distribution, the estimation of the parameters of SEMs by the method of Maximum Likelihood indicates that, due to the standard errors of the estimated parameters, the conclusions are not guaranteed. However, this violation of the condition of multivariate normality does not affect the capacity of the Maximum Likelihood method for estimating the parameters of the Model in an unbiased way. B. Efron's Botstrapp Method [11] has been used; this allows estimations of the standard errors of the Model's parameters to be obtained, independently of their distribution, by means of re-sampling techniques. This method, thus, also permits the determination of margins of validity for the estimations.

\section{Results and discussion}

The simplification of the EFQM Model essentially involves the reorganization of the 24 Enabler sub-criteria, by grouping them on a smaller number of dimensions. For this, the technique of factorial analysis has been applied to the scores of the 24 Enabler sub-criteria. The chosen method of extraction is that of principal components, using the condition that the magnitude of the eigenvalues should be higher than 1 (the $\mathrm{K} 1$ rule) as the extraction criterion.

Table 3 shows the mentioned eigenvalues, and the variances that correspond to each extracted factor. It can be appreciated that only two eigenvalues meet the criterion of extraction chosen (their value has to be higher than 1). Therefore, only for these factors, it has sense to present (see Table 4) the values for the extraction and rotation. 
Table III.

Explained variance by each factor in the extraction by the method of principal components.

\begin{tabular}{|c|c|c|c|c|c|c|c|}
\hline \multirow{2}{*}{ Factor } & \multicolumn{3}{|c|}{ Initial eigenvalues } & \multirow{2}{*}{ Factor } & \multicolumn{3}{|c|}{ Initial eigenvalues } \\
\hline & Total & $\begin{array}{l}\text { Variance } \\
(\%)\end{array}$ & $\begin{array}{l}\text { Cumulative } \\
(\%)\end{array}$ & & Total & $\begin{array}{l}\text { Variance } \\
(\%)\end{array}$ & $\begin{array}{l}\text { Cumulative } \\
(\%)\end{array}$ \\
\hline 1 & 14.341 & 59.754 & 59.754 & 13 & 0.300 & 1.251 & 91.179 \\
\hline 2 & 1.481 & 6.171 & 65.926 & 14 & 0.285 & 1.188 & 92.367 \\
\hline 3 & 0.838 & 3.491 & 69.417 & 15 & 0.283 & 1.180 & 93.547 \\
\hline 4 & 0.776 & 3.234 & 72.651 & 16 & 0.246 & 1.026 & 94.572 \\
\hline 5 & 0.734 & 3.057 & 75.707 & 17 & 0.234 & 0.977 & 95.549 \\
\hline 6 & 0.625 & 2.606 & 78.313 & 18 & 0.216 & 0.898 & 96.447 \\
\hline 7 & 0.601 & 2.504 & 80.818 & 19 & 0.207 & 0.861 & 97.308 \\
\hline 8 & 0.537 & 2.237 & 83.055 & 20 & 0.170 & 0.708 & 98.016 \\
\hline 9 & 0.500 & 2.085 & 85.140 & 21 & 0.130 & 0.543 & 98.559 \\
\hline 10 & 0.417 & 1.736 & 86.876 & 22 & 0.121 & 0.503 & 99.062 \\
\hline 11 & 0.393 & 1.637 & 88.513 & 23 & 0.117 & 0.489 & 99.551 \\
\hline 12 & 0.340 & 1.415 & 89.928 & 24 & 0.108 & 0.449 & 100.000 \\
\hline
\end{tabular}

Table IV.

Extraction and Rotation for those factors with initial eigenvalues higher than 1.

\begin{tabular}{|c|c|c|c|c|c|c|}
\hline \multirow[t]{2}{*}{ Factor } & \multicolumn{3}{|c|}{$\begin{array}{l}\text { Sum of the squares of the } \\
\text { correlations with each factor }\end{array}$} & \multicolumn{3}{|c|}{$\begin{array}{l}\text { Sum of the squares of the } \\
\text { correlations with each factor }\end{array}$} \\
\hline & Total & $\begin{array}{l}\text { Variance } \\
(\%)\end{array}$ & $\begin{array}{l}\text { Cumulative } \\
(\%)\end{array}$ & Total & $\begin{array}{l}\text { Variance } \\
(\%)\end{array}$ & $\begin{array}{l}\text { Cumulative } \\
(\%)\end{array}$ \\
\hline ( & 13.984 & 58.267 & & 7.883 & 32.844 & 32.844 \\
\hline 2 & 1.119 & 4.662 & 62.929 & 7.220 & 30.085 & 62.929 \\
\hline
\end{tabular}

The factorial solution has been rotated by the VARIMAX method to facilitate its interpretation. Table 5 shows the rotated factorial solution, that is, the correlations after the rotation between each of the original variables with each of the two factors considered.

Table V.

Rotated Factorial solution.

\begin{tabular}{|l|l|l||l|l|l|}
\hline Subcriterion & Factor 1 & Factor 2 & Subcriterion & Factor 1 & Factor 2 \\
\hline $1 \mathrm{a}$ & 0.71 & 0.49 & $3 \mathrm{~d}$ & 0.76 & 0.22 \\
\hline $1 \mathrm{~b}$ & 0.59 & 0.59 & $3 \mathrm{e}$ & 0.79 & 0.29 \\
\hline $1 \mathrm{c}$ & 0.68 & 0.47 & $4 \mathrm{a}$ & 0.66 & 0.42 \\
\hline $1 \mathrm{~d}$ & 0.77 & 0.37 & $4 \mathrm{~b}$ & 0.44 & 0.55 \\
\hline $2 \mathrm{a}$ & 0.62 & 0.41 & $4 \mathrm{c}$ & 0.30 & 0.48 \\
\hline $2 \mathrm{~b}$ & 0.61 & 0.53 & $4 \mathrm{~d}$ & 0.36 & 0.72 \\
\hline $2 \mathrm{c}$ & 0.43 & 0.67 & $4 \mathrm{e}$ & 0.46 & 0.56 \\
\hline $2 \mathrm{~d}$ & 0.40 & 0.60 & $5 \mathrm{a}$ & 0.21 & 0.73 \\
\hline $2 \mathrm{e}$ & 0.67 & 0.54 & $5 \mathrm{~b}$ & 0.39 & 0.69 \\
\hline $3 \mathrm{a}$ & 0.71 & 0.48 & $5 \mathrm{c}$ & 0.26 & 0.80 \\
\hline $3 \mathrm{~b}$ & 0.66 & 0.46 & $5 \mathrm{~d}$ & 0.40 & 0.74 \\
\hline $3 \mathrm{c}$ & 0.73 & 0.28 & $5 \mathrm{e}$ & 0.54 & 0.59 \\
\hline
\end{tabular}

The KMO index obtained is 0.950 . This value indicates that the estimated factorial model is in good agreement with the experimental data, since the closer the KMO value is to 1 , the better the data correspond to a factorial structure. By convention, when the KMO value is below 0.6, the fit is considered poor. Figure 2 represents graphically the rotated factorial solution. 


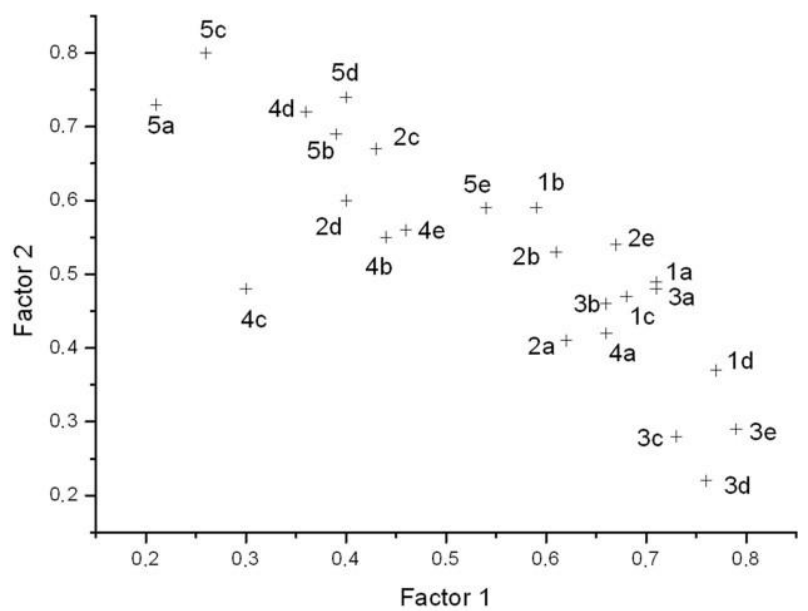

Figure 2. Rotated Factorial Solution.

As it can be appreciated in this graph, there is a group of sub-criteria (1d, $3 \mathrm{c}, 3 \mathrm{~d}$ and $3 \mathrm{e})$ that presents the strongest correlations with Factor 1, above 0.7, whereas their correlations with Factor 2 are the weakest, below 0.4:

1d. Leaders reinforce a culture of Excellence with the organization staff.

3c: People are involved and empowered.

$3 \mathrm{~d}$ : People and the organization have a dialogue.

3e: People are rewarded, recognized and cared for.

When observing Figure 2, it is also clear that another group of sub-criteria saturate on Factor 2:

5a: Processes are systematically designed and managed.

5c: Products and Services are designed and developed based on customer needs and expectations.

Other sub-criteria also present correlations higher than 0.7 with Factor 2, although their correlation with Factor 1 is somewhat higher than that of the preceding group:

$4 \mathrm{~d}$ : Technology is managed.

5d: Products and Services are produced, delivered and serviced.

Therefore, it can be concluded that Factor 1 correlates principally with the sub-criteria that have to do with relational aspects of the organization: the involvement of people, assumption of responsibilities, communication and dialogue with the organization, recognition and rewards, and compensation, to which can be added motivation and support. On the other hand, Factor 2 correlates mainly with the sub-criteria associated with the structural factors of the organization: design and systematic management of the processes of the organization, and design of the product, to which can be added the production and distribution of the product, and the management of the technology employed.

This result is consistent with the models proposed by several authors [12-16], that are centered on two unique dimensions. One of these dimensions groups together the "hard", technical and structural aspects, while the other dimension would bring together the "soft" or social and relational aspects.

From the results of the factorial analysis, a Simplified Model can be developed by joining the corresponding sub-criteria of the EFQM Model on each of the two factors identified. This Simplified Model is especially useful when the EnablersPerformance causal structure, proposed by the original full EFQM Model, can be reproduced. In order to compare the original Model with the Simplified Model the technique of Structural Equation Models has been utilized.

The model already studied [17], as shown in Figure 3 (a), has been taken as the reference for the original, full EFQM Model, in which the Criteria are determined by the latent variables, and the scores of each sub-criterion are used as indicators of the degree of excellence achieved on the related Criterion.

This Model incorporates the following causal relationships between the Enablers and the Results Criteria proposed by various authors:

- Processes $>$ Customers [18-23]

- Customers $>$ Performance [24-30]

- People>Customers $>$ Performance [31-33]

The following relationships have also been tested in the Full EFQM Model, since they are commonly considered by the evaluators in formal processes of evaluation:

- People>Performance in People:

- Alliances and Resources>Society:

The Simplified Model of Figure 3 (b) incorporates causal relationships similar to those of the Full EFQM Model, taking into account the reorganization of sub-criteria in the two factors considered. 


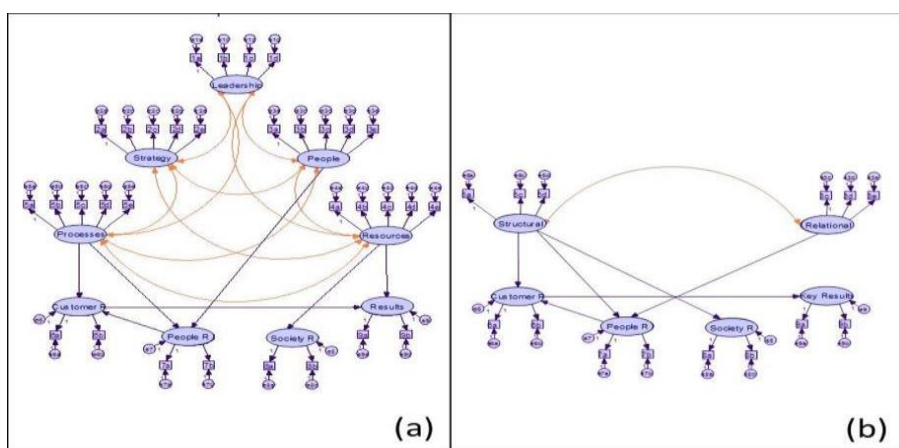

Figure 3. (a) EFQM Full Model and (b) Simplified Model.

The parameters for the Full and Simplified EFQM Models are shown in Tables 6 and 7, respectively. The estimation of these parameters have been carried out using the method of Maximum Likelihood, together with the lower and upper limits of the confidence interval of $95 \%$ for these parameters, calculated by the Bootstrapping of 500 samples, and corrected with respect to the bias. Finally, these two models have been compared to the data. The Goodness of Fit indices obtained from this comparison are presented in Table 8.

Table VI.

Estimations of the structural coefficients of the full EFQM Model.

\begin{tabular}{|c|c|c|c|c|c|c|}
\hline \multicolumn{3}{|c|}{ Structural coefficient } & Estimation & Lower & Upper & $\mathrm{P}$ \\
\hline People R & $<---$ & People & 0.302 & 0.089 & 0.557 & 0.007 \\
\hline People R & $<--$ & Processes & 0.358 & 0.097 & 0.635 & 0.006 \\
\hline Customers R & $<---$ & Processes & 0.232 & -0.064 & 0.471 & 0.113 \\
\hline Customers R & $<---$ & People R & 1.007 & 0.760 & 1.444 & 0.004 \\
\hline Results & $<---$ & Resources & 0.354 & 0.103 & 0.586 & 0.012 \\
\hline Society R & $<---$ & Resources & 0.649 & 0.424 & 0.912 & 0.006 \\
\hline Results & $<---$ & Customers R & 0.620 & 0.467 & 0.825 & 0.003 \\
\hline \multicolumn{3}{|l|}{ Correlations } & Estimation & Lower & Upper & $\mathrm{P}$ \\
\hline Strategy & $\langle--\rangle$ & Processes & 0.873 & 0.799 & 0.923 & 0.008 \\
\hline Leadership & $\langle-->$ & Strategy & 0.938 & 0.889 & 0.976 & 0.005 \\
\hline Leadership & $\langle--\rangle$ & People & 0.904 & 0.837 & 0.952 & 0.004 \\
\hline Leadership & $\langle--\rangle$ & Processes & 0.840 & 0.741 & 0.915 & 0.005 \\
\hline Leadership & $\langle--\rangle$ & Resources & 0.832 & 0.735 & 0.923 & 0.003 \\
\hline People & $\langle--\rangle$ & Processes & 0.797 & 0.677 & 0.870 & 0.007 \\
\hline Strategy & $\langle--\rangle$ & Resources & 0.917 & 0.857 & 0.962 & 0.006 \\
\hline Strategy & $\langle--\rangle$ & People & 0.894 & 0.808 & 0.935 & 0.010 \\
\hline Resources & $\langle--\rangle$ & Processes & 0.883 & 0.792 & 0.933 & 0.013 \\
\hline People & $\langle--\rangle$ & Resources & 0.853 & 0.764 & 0.913 & 0.003 \\
\hline
\end{tabular}

Table VII.

Estimations of the structural coefficients of the Simplified Model.

\begin{tabular}{|c|c|c|c|c|c|c|}
\hline & \\
\hline Structural coe & cient & & Estimation & Lower & Upper & $\mathrm{P}$ \\
\hline People R & $<--$ & Relational & 0.35 & 0.129 & 0.56 & 0.004 \\
\hline People R & $<--$ & Structural & 0.372 & 0.167 & 0.636 & 0.004 \\
\hline Customers R & $<--$ & Structural & 0.304 & 0.018 & 0.558 & 0.037 \\
\hline Customers R & $<--$ & People R & 0.961 & 0.704 & 1.355 & 0.004 \\
\hline Key Results & $<--$ & Customers R & 0.854 & 0.719 & 1.018 & 0.004 \\
\hline Society & $<--$ & Structural & 0.59 & 0.357 & 0.816 & 0.004 \\
\hline Correlations & & & Estimation & Lower & Upper & $\mathrm{P}$ \\
\hline Relational & $\langle--\rangle$ & Structural & 0.689 & 0.514 & 0.811 & 0.004 \\
\hline
\end{tabular}

Table VIII.

Indices of Goodness of Fit for both models.

\begin{tabular}{|l|l|l|}
\hline \multicolumn{3}{|l|}{ Comparison of Models } \\
\hline Index & Full & Simplified \\
\hline CMIN/DF & 2.321 & 2.734 \\
\hline GFI & 0.729 & 0.873 \\
\hline CFI & 0.874 & 0.920 \\
\hline RMSEA & 0.089 & 0.102 \\
\hline ECVI & 7.182 & 1.565 \\
\hline
\end{tabular}


Although the CMIN/DF index shows a slightly better fit of the EFQM Model, the CFI and GFI indices indicate a better fit for the Simplified Model. In the same way, although the RMSEA index demonstrates a slightly better fit for the original EFQM Model, the ECVI index clearly points that the Simplified Model adjusts better to the experimental data.

These results prove that the Simplified Model is in great agreement (as good as the one achieved by the Full EFQM Model) with the data of the sample.

\section{Conclusions}

It has been found that the 24 Enabler sub-criteria of the EFQM Model can be regrouped on two factors, rather than on the five original Enabler Criteria. The first factor correlates principally with the sub-criteria associated with relational aspects of the organization; whereas the second factor correlates principally with the sub-criteria associated with the structural factors of the organization. This result is consistent with the models proposed by several authors, which focus on two particular dimensions.

One of these dimensions joins the "hard" or structural aspects, while the other dimension brings together the "soft" or social and relational aspects.

The authors presented a Simplified EFQM Model, which requires only the evaluation of 6 Enabler sub-criteria, in contraposition to the 24 sub-criteria of the original model. This model agrees with the experimental data of the studied case at a degree as good as the Full EFQM Model. This Simplified Model contemplates two independent variables: Structural and Relational, as the causes of the various Performance variables. This Model shows the significant relationships of the Structural variable with the performance regarding the Customers, People and Society. The relationship of the Relational variable with the results in respect of People is also significant. The relationships, confirmed in previous models, of the performance in respect of People with the results in respect of Customers, and of these with the Key Results, are maintained in this model. This Simplified Model is proposed as the best one for evaluating the degree of excellence achieved by an organization that require a greatly reduced effort, but that reproduce the causal structure of the original EFQM model.

\section{References}

[1].A. Wendt, M. Amblard, et al. 2014 Annual Report, European Foundation for Quality Management. Brussels (Belgium). 2015.

[2].European Foundation for Quality Management. Modelo EFQM de Excelencia. Brussels (Belgium) 2003.

[3].G. K. Kanji and S. Kanji, "Business Scorecard”. Total Quality Management, vol. 13, pp. 13-27 (2002).

[4].A. H. Westlund "Is there a correlation between business excellence and financial performance?" Lucerne: Presentation at the EFQM Forum 2001, 10-12 October 2001.

[5].L. Ritchie and B. G. Dale, "Self-assessment using the bussiness excelence model: a study of practice and process". International Journal of Production Economics, vol. 66, pp. 241-254 (2000).

[6].J. J. Tari Guilló, et al. "El proceso de autoevaluación según el Modelo EFQM en una PYME". Investigaciones Europeas de Dirección y Economía de la Empresa, vol. 13, pp. 203-216 (2007).

[7].C.A. Cerny and H.F. Kaiser, "A study of a measure of sampling adequacy for factor-analytic correlation matrices". Multivariate Behavioral Research, vol. 12, pp. 43-47 (1977).

[8].C. D. Dziuban, and E. C. Shirkey, "When is a correlation matrix appropriate for factor analysis?" Psychological Bulletin, vol. 81, pp. 358-361 (1974).

[9].H.F. Kaiser, “A second generation Little Jiffy". Psychometrika, vol. 35, pp. 401-415 (1970).

[10]. J.B. Ullman. Structural equation modelling (chapter of the book "Using Multivariate Statistics", Third Edition, B.G. Tabachnick and L.S. Fidell, Eds.). Harper Collins College Publishers. New York (USA). 1996.

[11]. B. Efron, "Bootstrap methods: another look at the jackknife". The Annals of Statistics, vol. 7, pp. 1-266 (1979).

[12]. J. A. Dotchin and J. S. Oakland, “Theories and concepts in Total Quality Management”. Total Quality Management, vol. 3, pp. 133-145 (1992).

[13]. A. Wilkinson, "The other side of quality: the "soft" issues and human resource dimension". Total Quality Management, vol. 3, pp. 323-329 (1992).

[14]. S. Black and J.L. Porter, “An empirical model for Total Quality Management”. Total Quality Management, vol. 6, pp. 149-164 (1995).

[15]. R. J. Boaden, “What is Total Quality Management and does it matter?”. Total Quality Management, vol. 8, pp. 153171 (1997).

[16]. A.Wilkinson, et al Managing with Total Quality Management: Theory and practice. Mac Millan Press, London (UK). 1998.

[17]. F. Tejedor-Panchon, et al. "Relaciones causales en el Modelo Europeo de Excelencia". DYNA Ingeniería e Industria. vol. 86, pp. 656-661 (2011).

[18]. F. X. Frei, P. T. Harker, L. Hunter, Inside the Black Box: What Makes a Bank Efficient, Ed. by University of Pennsylvania. Philadelphia (USA). 1997.

[19]. N. Tsikriktsis and J. Heineke, "The impact of process variation on customer dissatisfaction: evidence from the U.S. domestic airline industry”. Decision Sciences. vol. 35, pp. 129-142 (2004).

[20]. W. E. Deming, Quality, productivity and competitive position. Cambridge MA: MIT Center for Advanced Engineering Study. Cambridge (USA). 1982.

[21]. J. M. Juran, Juran on planning for quality. Free Press. New York (USA). (1988). 
[22]. G. Taguchi, Introduction to quality engineering: Designing quality into products and processes. Ed. Quality Resources. Tokyo (Japan) 1986.

[23]. V. A. Zeithaml, "Service quality, profitability, and the economic worth of customers: what we know and what we need to learn". Journal of the Academy of Marketing Science. vol. 28, pp. 67-85 (2000).

[24]. M. T. Koska, "High quality care and hospital profits: is there a link?”. Hospitals, vol. 5, pp. 62-63 (1990).

[25]. E. Nelson, R. T. Rust, A. Zahorik, et al. "Do patient perceptions of quality relate to hospital financial performance?". Journal of Healthcare Marketing, vol. 12, pp. 6-13 (1992).

[26]. D. A. Aaker and R. Jacobson, “The financial information content of perceived quality”. Journal of Marketing, vol. 58, pp. 191-201 (1994).

[27]. E. W. Anderson, C. Fornell, D. R. Lehrmann, “Customer Satisfaction, Market Share, and Profitability: Findings from Sweden". Journal of Marketing, vol. 58, pp. 53-66 (1994).

[28]. R. Buzzell and B. Gale, The PIMS Principles: Linking Strategy to Performance, Free Press. New York (USA). 1987.

[29]. R. Hallowell, "The relationship of customer satisfaction, customer loyalty and profitability: an empirical study". International Journal of Service Industry Management. vol. 7, pp. 27-42 (1996).

[30]. C. Fornell, "A national customer satisfaction barometer: the Swedish experience”. Journal of Marketing, vol. 56, pp. 6-21 (1992).

[31]. B. Schneider, J. J. Parkington, V. M. Buxton, "Employee and Customer Perceptions of Service in Banks". Administrative Science Quarterly. vol. 25, pp. 252-267 (1980).

[32]. F. Reichheld, The Loyalty Effect: The Hidden Force Behind Growth, Profits and Lasting Value, Harvard Business School Press, Boston (USA). 1996.

[33]. R. Brooks, “Why Loyal Employees and Customers Improve the Bottom Line”. Journal for Quality \& Participation, vol. 23, pp. 40-44 (2000). 